\title{
A NOVA ECONOMIA E A EDUCAÇÃO
}

\author{
Artur Carlos Crespo Martins Cabugueira*
}

Pretendemos, neste artigo, dar um contributo para a análise das repercussões que a chamada "Nova Economia" poderá ter no seio dos sistemas educativos, no que se refere aos processos, conteúdos e formas de aprendizagem.

Começámos por fazer uma abordagem da questão central: "A Nova Economia existe? O que é a Nova Economia?" Apresentámos, desta forma, as opiniões, os argumentos utilizados pelas duas correntes de opinião que se debruçaram sobre o tema - os defensores e os opositores à ideia da existência duma "Nova Economia".

Embora a discussão em torno desta questão esteja longe de estar concluída, avançámos com a nossa posição sobre a temática, através da constatação, na sociedade actual, desde os meados da década de 90, da ocorrência de um conjunto de fenómenos económicos novos que, efectivamente, poderão consubstanciar um novo fenómeno económico, o qual poderá ser designado por "Nova Economia".

Fizemos, de seguida, uma análise sucinta da "Nova Economia", através da apresentação dos seus principais elementos $e$ características, comparando-os com os correspondentes relativos à " Velha Economia".

Finalmente, examinámos as alterações fundamentais que os sistemas de educação sofrerão no âmbito da "Nova Economia", contrastando as características básicas do sistema de educação

\footnotetext{
* Assistente da Universidade de Trás-os-Montes e Alto Douro (Extensão de Chaves).
} 
tradicional, baseado na instrução e um sistema novo baseado na aprendizagem.

Palavras-chave: Tecnologias de informação e comunicação, globalização, Internet, instrução/aprendizagem, conhecimento.

\section{OS MITOS SOBRE A NOVA ECONOMIA}

Quase todos concordam que algumas economias, particularmente a dos Estados Unidos da (EUA), sofreram mudanças fundamentais nos últimos 15 anos. A grande questão coloca-se em relação ao facto de se saber se elas constituem uma nova economia (NE), ou seja, se aquilo a que se designa por NE é um mito ou se é, na realidade, um novo fenómeno económico.

Há argumentos tanto a favor como contra a ideia da NE constituir um novo paradigma económico.

Os pessimistas, que afirmam que a ideia duma NE é um mito, enfatizam e exageram os seus pontos fracos, enquanto subvalorizam os seus aspectos mais positivos. Eles censuram a tecnologia e a globalização, a estagnação salarial, a desigualdade de crescimento e a degradação ambiental. Por outro lado, afirmam que a NE facilitou a desindustrialização e que as mudanças tecnológicas anulam mais empregos do que geram, para além do facto de a maior parte dos empregos criados na NE serem empregos de salários baixos.

Por vezes estes argumentos conduzem a posições internamente contraditórias. Esses economistas argumentam que se as empresas instalam tecnologia, os trabalhadores são despedidos; mas, se elas não a instalam, então consomem os lucros e não os reinvestem para elevar os salários. Os pessimistas realçam correctamente que a mudança económica gera perdedores assim como ganhadores. Porém, a sua solução preferida é muitas vezes retardar ou parar o processo de mudança. Assim, prescrevem a proteç̧ão comercial, a regulamentação top-down e a utilização de ultrapassados programas burocráticos da era industrial. A sua "terra de leite e mel" é constituída por grandes organizações com emprego seguro, mercados e concorrência estáveis, o que consubsta expectativas irrealistas no contexto das tendências fundamentais na NE.

Pelo contrário, todos os que defendem que a $\mathrm{NE}$ constitui um novo paradigma económico acreditam que se verifica um elevado crescimento, 
baixas condições inflacionistas, com baixo desemprego. Eles argumentam que a produtividade está a aumentar de tal forma que pode proporcionar o pagamento de aumentos salariais, enquanto ao mesmo tempo elevar os lucros.

Encaram esta nova era com grandes possibilidades para o crescimento e criatividade; pretendem a eliminação de toda a regulamentação tecnológica, opõem-se à concessão de fundos governamentais para a investigação e desenvolvimento (excluindo a defesa).

A sua "terra de leite e mel" é constituída por pequenas empresas e empresários individuais em mercados dinâmicos; a desigualdade dos rendimentos mais elevados, o que incentivaria um esforço mais árduo; uma forte redução do papel do governo, incluindo papéis reduzidos no desenvolvimento da tecnologia, educação e formação.

Em relação aos argumentos dos pessimistas contrapõem nomeadamente que:

- a industrialização (particularmente nos EUA) não está a diminuir, mas está a ser "reinventada", com as empresas a efectuarem um reforço num novo tipo de investimentos em tecnologia, formação e novas formas de organização do trabalho;

- a estagnação dos salários reais é um dos resultados do baixo crescimento de produtividade da economia no seu todo. Enquanto a desigualdade dos rendimentos está ligada à mudança tecnológica, à imigração e ao declínio do sindicalismo, a totalidade do rendimento salarial da economia está ligada ao crescimento de produtividade;

- embora o número de empregados de baixos salários esteja a aumentar, o número de empregos de salários elevados está a crescer de forma ainda mais rápida;

- a mudança tecnológica não anula mais empregos do que gera, a tecnologia altera a composição dos empregos e aumenta a produtividade e os rendimentos, mas não aumenta a taxa natural de desemprego. Pelo contrário, a dinâmica da NE reduziu as taxas de desemprego. As novas tecnologias incentivam o declínio nos empregos no sector primário. Contudo, como os produtos agrícolas se tornaram mais baratos, os consumidores dispendem os seus rendimentos disponíveis noutros tipos de bens (p. ex. automóveis, electrodomésticos), estimulando o emprego noutros sectores. Como as novas tecnologias de informação começam a elevar as taxas de crescimento da produtividade, esta mesma dinâmica 
positiva continuará a conduzir a mais altos rendimentos e não a um menor número de empregos;

- as tendências de dispersão da NE não significam a eliminação das grandes sociedades e o declínio do governo. As grandes empresas e o governo estão a "reinventar" as suas funções e ainda desempenham, no mínimo, papéis-chave na economia.

Dado que as tecnologias de informação permitem às empresas chegar a mais vastos mercados e tirar partido das economias de escala, a dimensão média das empresas na NE está a aumentar, não a diminuir. Além disso, tal como a Internet não significou o fim das grandes empresas, também não pressagia o fim do governo. Antes, cria a exigência para que os governos se predisponham a ser mais rápidos, mais flexíveis e dinâmicos.

Em conclusão, podemos dizer que o debate em torno desta questão emergência ou não dum fenómeno económico novo designado por NE está longe de ser pacífico e de estar encerrado.

Por um lado, aconteceu que desde a segunda metade da década de 90, os Estados Unidos registaram, correlacionados com os maiores investimentos no domínio das novas tecnologias de informação e comunicação (TIC) e a chegada da Internet, maiores índices de crescimento económico com baixas taxas de inflação e maior produtividade do trabalho.

Por outro, há quem sustente que tais performances são explicadas por factores temporários/conjunturais: $\mathrm{o}$ aumento do crescimento da produtividade em 1996-97 é considerado demasiado recente de forma a argumentar que representa uma tendência de longo prazo na produtividade; por exemplo o crescimento de produtividade foi muito modesto entre 1990 e 1995. Dois anos não traduzem uma tendência.

Para outros autores ainda, embora alguns estudos tenham demonstrado a existência dum vínculo entre as altas taxas de investimento em tecnologias de informação e o aumento da produtividade nos Estados Unidos, em outros países, como o Canadá, Reino Unido, Alemanha e França, o panorama é menos claro.

Para estes autores, e de acordo com os critérios que adoptam - taxas de crescimento da produtividade progressivamente mais elevadas, derivadas, por sua vez, principalmente da produção, adopção e difusão contínua de TIC - nenhuma das economias atrás referidas reúne ainda as condições para serem designadas por N.E.. 
Contudo, e para finalizar, é nossa opinião que, no campo económico, e desde os meados da década de 90, alguns fenómenos novos estão a emergir em consequência do aparecimento e utilização das TIC.

Parece-nos que estes novos fenómenos não são simplesmente uma abstracção - tocam cada pessoa, todas as pessoas, em cada passo da sua vida.

Se a este conjunto de fenómenos quisermos dar o nome de NE, então sim, afirmaremos que existe efectivamente uma NE.

Mas o debate continua...

\section{A NOVA ECONOMIA: ALGUNS CONCEITOS BÁSICOS, COMPONENTES E CARACTERÍSTICAS}

O forte crescimento económico registado nos Estados Unidos na segunda metade da década de noventa, com baixas taxas de inflação e aumento da produtividade da mão-de-obra, levou muitos observadores a anunciar o nascimento de uma "nova economia" ligada aos avanços no campo das TIC.

Embora o termo "nova economia" tenha despertado um grande interesse, não há um acordo quanto aos factores que determinaram o crescimento das economias (particularmente a dos Estados Unidos), nem sequer sobre o que é a "nova economia" (NE).

Vejamos, então de seguida, alguns conceitos que, frequentemente, são veiculados sobre este novo fenómeno.

Para De Masi, Estevão e Kodres (2001: 38-41) a NE pode definir-se com uma economia caracterizada por uma maior taxa de crescimento a longo prazo determinada por uma taxa de crescimento da produtividade persistentemente mais alta, derivada, por sua vez, principalmente da produção, adopção e contínua difusão de TIC. Para estes autores um dos aspectos característicos mais frequentemente mencionados da NE é o crescimento mais rápido do produto potencial, com baixas pressões inflacionistas.

Para outros autores o termo NE refere-se a um conjunto de mudanças quantitativas e qualitativas que, nos últimos 15 anos, transformaram a estrutura, o funcionamento e as regras da economia.

A NE é uma economia baseada no conhecimento, cujas as chaves para a criação de empregos e de mais elevados padrões de vida são as ideias inovadoras e a tecnologia envolvida nos serviços e nos produtos 
industriais. É uma economia onde o risco, a incerteza e a mudança constante são a regra, em vez de excepção.

Para o Kiel Institute of World Economics (2000), no essencial, a NE é uma economia onde simultaneamente os outputs finais e os inputs intermédios consistem predominantemente em informação. Quase sinónimos são os termos "Economia de Informação", "Economia baseada no Conhecimento" e "Economia Virtual". A "Economia da Internet" e a "E - Economia" são subconjuntos da NE.

A NE é principalmente conduzida por modernas tecnologias de informação e comunicação, as quais dão acesso a qualquer tipo de informação duma maneira ubíqua numa escala verdadeiramente global.

A NE, para outros, é uma noção difícil de definir e que não se percebe ainda em que consiste verdadeiramente. De qualquer forma, há unanimidade quanto ao facto de englobar a mundialização e a informatização de todos os processos de produção e meios de troca. Trata-se duma transformação fundamental que está em vias de revolucionar a maneira como trabalhamos e como tratamos os negócios nos mercados, tanto nacionais como internacionais.

A definição da NE contém muitas vezes termos como mundialização, redes, conhecimento, interdependência, inovação e produtividade.

Após algum trabalho de consulta de parte da respectiva literatura, chegámos à conclusão que a nossa impressão inicial estava provavelmente correcta - há pelo menos tantas definições de NE como pessoas que usam o termo.

As consultas realizadas possibilitaram-nos, contudo, a reunião de um conjunto comum de aspectos relacionados com a $\mathrm{NE}$, no que concerne às suas componentes e características.

As componentes mais comuns da NE são as seguintes:

1) Crescimento Tecnológico. O crescimento tecnológico pode elevar a produtividade do trabalho mediante, por um lado, o aumento do capital das TIC em relação ao trabalho, de forma a que se incremente a produção e, por outro, a modificação da interacção entre capital e trabalho (melhores técnicas e organização); de modo a aumentar a produção, ainda que o volume de capital e de mãode-obra utilizados seja o mesmo, ou seja, aumento da produtividade total dos factores.

2) Globalização. O mundo está crescentemente a tornar-se um mercado global. A expansão do comércio e integração financeira são muito mais do que processos tranquilos relativamente ao que normalmente é descrito nos media, mas a NAFTA, a integração 
monetária europeia, assim como as crises na Ásia, muitas vezes colocam a globalização na "Nova" categoria.

O capitalismo está a expandir-se em todo o mundo, através da introdução das forças do mercado, maior liberdade de comércio e expansão da desregulamentação. Na NE, os negócios traduzem-se por investimentos realizados globalmente para obter mercados, tecnologia e conhecimento.

3) Revolução na informação tecnológica, a Internet $e$ as novas indústrias. A tecnologia encurtou os ciclos entre a introdução dum produto no mercado e a sua eventual substituição. As tecnologias de informação estão a crescer com eficiência e a reduzir os custos. As escolhas dos consumidores expandem-se, enquanto os custos da informática e de transmissão de dados se reduzem. A revolução na informação tecnológica verifica-se à volta de todos nós: o fax, telemóveis, computadores, modems, a Internet. Mas mais do que isto.

Esta tecnologia digital está a criar novas empresas e novas indústrias que se desenvolvem rapidamente e vendem para o mundo inteiro. Como exemplos significativos pode referir-se o caso de Sillicon Valley (EUA), onde 11 novas empresas são criadas todas as semanas ou o da Yahoo (EUA) que se desenvolveu em menos de cinco anos, passando dum serviço criado por dois estudantes a uma sociedade mais importante que a Boeing, em termos de capitais.

Por outro lado, a economia nos países mais desenvolvidos já não se organiza em torno da produção de bens estandardizados em série e em grandes empresas. Nesses países (particularmente nos EUA), actualmente $80 \%$ dos trabalhadores encontram-se em escritórios processando ou gerando informação ou providenciando serviços às pessoas.

Todavia, acrescente-se que a NE não se restringe às empresas dos sectores de alta tecnologia, são também empresas tradicionais que dela podem beneficiar, como, por exemplo, uma empresa familiar portuguesa, de porcelanas, que, através do seu site na Internet, assegura os empregos vendendo para o Japão.

Ao nível estrutural a NE apresenta, entre outras, as seguintes características:

1) Economia do imaterial. Cada informação - dados, textos, sons imagens, programas - pode ser distribuída pela rede, reduzindo o custo da produção a um custo de pesquisa.

2) Substituição dos intermediários. Compra em bolsa, vender um bem imobiliário, comparar os preços de diferentes produtores. A cadeia 
dos intermediários tradicionais é substituída por um site que permite o acesso a toda a informação disponível.

3) Preços dinâmicos. As "compras em leilão" desenvolvem-se na net em todos os domínios: bilhetes de avião, camas de hotel, etc., deixando ao consumidor o cuidado de fixar o preço do mercado.

4) Uma redução dos stocks. A Internet permite ligar os intermediários aos seus distribuidores, a produção é realizada em tempo real à procura do cliente, suprimindo os stocks.

A "antiga economia" baseava-se em fábricas com as suas cadeias de montagem, as suas chaminés industriais e, por vezes, as suas difíceis condições de trabalho. A economia industrial permitiu uma melhoria do nível de vida relativamente à economia agrícola que a tinha precedido. Ela também foi o resultado do progresso técnico. A economia de hoje é o resultado duma mudança tecnológica, mas esta é duma natureza completamente diferente. Com efeito, doravante a tecnologia será um factor de produção cada vez mais importante, mais que o capital ou a mão-de-obra. Numa economia baseada no conhecimento, a informação e as ideias suplantam os bens e os serviços materiais como elementos primários de produção e de consumo.

A transição para a NE, que agora começa a tomar lugar, está associada com mudanças fundamentais na escassez de factores: na economia agrícola, a terra era escassa e o trabalho era abundante. Na sociedade industrial, o capital físico era (é) escasso e as matérias-primas (incluindo o ambiente) são abundantes. Na NE, a informação é abundante. Qual é o novo factor escasso? O capital humano? A capacidade para aprender?

As propriedades da informação como um bem económico são significativamente diferentes das propriedades dos bens típicos produzidos pela "velha economia": a informação é um bem público, um bem experimental e é susceptível de gerar economias de escala na produção e consumo.

Para resumir as principais mudanças que se observam com a NE, apresentamos o quadro que se segue (Quadro 1): 
Quadro 1

CARACTERÍSTICAS DA “ANTIGA” VERSUS AS DA "NOVA ECONOMIA"

\begin{tabular}{|c|c|c|}
\hline & "Antiga Economia" & "Nova Economia" \\
\hline \multicolumn{3}{|l|}{ Características económicas } \\
\hline Mercados & Estáveis & Dinâmicos \\
\hline Competição & Nacional & Global e local \\
\hline Organização & Hierarquizada, burocrática & Em rede \\
\hline Emprego & $\begin{array}{l}\text { Estabilidade de emprego, } \\
\text { emprego a tempo inteiro }\end{array}$ & $\begin{array}{l}\text { Emprego precário, trabalho no } \\
\text { domicílio, trabalho autónomo }\end{array}$ \\
\hline Organização de produção & Produção em massa & $\begin{array}{l}\text { Indústria do conteúdo, } \\
\text { produção flexível }\end{array}$ \\
\hline \multicolumn{3}{|l|}{ Indústria } \\
\hline Factores de produção & Capital / trabalho & Inovação / conhecimento \\
\hline Factores de competitividade & Mecanização & Numerização \\
\hline $\begin{array}{ll}\text { Fontes de vantagens } \\
\text { comparativas }\end{array}$ & $\begin{array}{l}\text { Baixos custos e economias } \\
\text { de escala }\end{array}$ & Inovação, qualidade, custo \\
\hline Relações entre empresas & Solitária & Alianças e colaboração \\
\hline \multicolumn{3}{|l|}{ Massa salarial } \\
\hline Fins políticos & Pleno emprego & $\begin{array}{l}\text { Adaptatividade e mais } \\
\text { elevados rendimentos }\end{array}$ \\
\hline Competências & Competências específicas & $\begin{array}{l}\text { Competências variadas e } \\
\text { transdisciplinares }\end{array}$ \\
\hline Educação requerida & $\begin{array}{l}\text { Uma competência ou um } \\
\text { diploma }\end{array}$ & $\begin{array}{l}\text { Uma aprendizagem para } \\
\text { a vida }\end{array}$ \\
\hline Gestão do pessoal & Adversidade & Colaboração \\
\hline \multicolumn{3}{|l|}{ Governo } \\
\hline Relações nos negócios & Regularizar & Encorajar o crescimento \\
\hline Regulamentação & Comando e controlo & $\begin{array}{l}\text { Instrumentos de medida } \\
\text { do mercado, flexibilidade }\end{array}$ \\
\hline \multicolumn{3}{|l|}{ Técnicas } \\
\hline Características e meios & $\begin{array}{l}\text { Analógicos (TV), micro- } \\
\text { computadores } \\
\text { suporte de papel }\end{array}$ & $\begin{array}{l}\text { Numéricas (Cdrom), rede de } \\
\text { redes, suporte electrónico } \\
\text { interactivo (ex.: Internet) }\end{array}$ \\
\hline \multicolumn{3}{|l|}{ Sociológicas } \\
\hline Características & $\begin{array}{l}\text { Sociedade industrial, escassez } \\
\text { de informação, introdução às } \\
\text { TIC }\end{array}$ & $\begin{array}{l}\text { Sociedade da informação, } \\
\text { abundância de informação, } \\
\text { apropriação das TIC }\end{array}$ \\
\hline
\end{tabular}

Fonte: Elaboração própria, 2001. 


\section{NOVA ECONOMIA - NOVA ESCOLA}

Nova Economia, nova realidade. Esta transição entre a economia de serviço e a economia do conhecimento coloca vários problemas. Que situações encontrarão os jovens no mercado de trabalho? Estarão preparados para fazer face à procura crescente das empresas relativamente aos seus conhecimentos, às suas competências?

Um elemento essencial da formação dos jovens, tendo em vista a obtenção de emprego, é a formação recebida através do sistema de educação. Terá ele sabido adaptar-se às mudanças económicas, sociais e tecnológicas? A instrução recebida estará à altura das exigências do mercado, ou o sistema de educação e os seus programas permanecem os mesmos, apesar da aparição da auto-estrada da informação e dos sistemas multimediáticos no interior das escolas?

Duma forma geral, os empregadores, na maioria dos países, acusam o sistema de educação da sua dificuldade em fornecer um número suficiente de especialistas de que as empresas necessitam, a sua falta de abertura à realidade das empresas e a sua lentidão em se adaptar à evolução das necessidades da economia do conhecimento.

Certos especialistas (Bibeau, R; 1997) sublinham que o fraco rendimento do sistema escolar e a sua incapacidade para responder às exigências da NE se explicaria, entre outros factores, pelo facto da escola constituir o último bastião onde as TIC não foram ainda verdadeiramente integradas. Ora, se a escola não participa na revolução tecnológica, colhe o risco de se isolar do resto da sociedade. Será necessário uma ruptura efectiva, de forma a instaurar um sistema de educação em correspondência com o meio envolvente. O papel principal do sistema educativo é responsabilizar os alunos em relação à sua própria formação, dar-lhes o poder de desenvolver as suas próprias competências e a capacidade de trabalhar num ambiente tecnológico de vanguarda complexo, no seio do qual a utilização intensiva das TIC seja generalizada.

Contudo, o panorama também não é assim tão negro. Focos de inovação nascem um pouco por toda a parte e os diversos níveis governamentais de cada país elaboram estratégias agressivas, seja para aumentar o número de computadores por aluno e ligar os estabelecimentos de ensino à Internet, seja para fazer da escola um lugar de aprendizagem e de domínio das novas tecnologias. 
Qual é o potencial das novas tecnologias para transformar a formação? As novas tecnologias e os novos meios de aprendizagem permitem repensar o acto de aprender e agem, na educação e formação, como poderosos instrumentos da abordagem baseada na aprendizagem: o paradigma da instrução dá lugar ao paradigma da aprendizagem. As novas tecnologias de aprendizagem vêm transformar radicalmente os fins e as práticas da pedagogia tradicional. O papel do formador e do aluno, bem como a interacção entre eles são incentivados a transformar-se. O formador deixa de ser um orador e um "difusor de montes de conhecimentos", para se tornar um tutor ou um acompanhante pronto a ajudar os alunos a moverem-se numa base de conhecimentos e a partilharem o saber, as dificuldades e os resultados. $\mathrm{O}$ aluno, por sua vez, em cooperação com os seus colegas, toma a responsabilidade da sua formação e constrói activamente os seus conhecimentos e os seus saberes.

Por outro lado, num ambiente complexo onde os saberes rapidamente se tornam obsoletos, as tecnologias de aprendizagem permitem oferecer uma formação simultânea, interactiva e individualizada, quer dizer, adaptada ao ritmo de aprendizagem dos alunos.

Em suma, as TIC põem em causa todos os elementos tradicionais de formação e da aprendizagem. Criam oportunidades para fazer emergir uma abordagem renovada que virá "contaminar" a escola, a Universidade, as organizações e as comunidades.

$\mathrm{O}$ quadro que se segue (Quadro 2) sintetiza as principais diferenças entre a abordagem tradicional, baseada na instrução e a abordagem renovada baseada na aprendizagem. 
Quadro 2

ABORDAGEM TRADICIONAL "VERSUS"

ABORDAGEM RENOVADA

\begin{tabular}{|c|c|}
\hline $\begin{array}{c}\text { Abordagem tradicional baseada na } \\
\text { instrução }\end{array}$ & $\begin{array}{c}\text { Abordagem renovada baseada na } \\
\text { aprendizagem }\end{array}$ \\
\hline \multicolumn{2}{|l|}{ Fins } \\
\hline Veicular instruções & Produzir aprendizagens \\
\hline Oferecer programa de formação & Criar ambientes de aprendizagem \\
\hline Rendimento a curto prazo & Autonomia, criatividade, adaptação constante \\
\hline \multicolumn{2}{|l|}{ Pedagogia / método de aprendizagem } \\
\hline Orientada para o instrutor & Orientada para o aluno \\
\hline Transmissão de conhecimentos pelo instrutor & Construção dos conhecimentos pelo aluno \\
\hline Lugares de difusão limitados & Lugares de difusão múltiplos \\
\hline Formação acessível em horários fixos & $\begin{array}{l}\text { Intemporalidade - conteúdos acessíveis em } \\
\text { qualquer momento }\end{array}$ \\
\hline Standard: mesmo ritmo para todos & $\begin{array}{l}\text { Individualizado: adaptado ao ritmo de cada } \\
\text { um }\end{array}$ \\
\hline Linear e cumulativa & Interactiva \\
\hline Avaliação no fim da formação & Avaliação ao longo de todo o processo \\
\hline Competitiva e individualista & Colaborativa, cooperativa e estimulante \\
\hline \multicolumn{2}{|l|}{ Papel do formador } \\
\hline Orador: controla o processo de aprendizagem & $\begin{array}{l}\text { Acompanhador: orienta o processo de } \\
\text { aprendizagem }\end{array}$ \\
\hline Detentor e transmissor do saber & Facilitar a aprendizagem e a autonomia \\
\hline \multicolumn{2}{|l|}{ Papel do aluno } \\
\hline Passivo, aceita & Activo, confronta, questiona. \\
\hline
\end{tabular}

Fonte: Adaptação de Audet, Jacob, Rondeau (1996) e de Longpré (1999).

Não obstante os inconvenientes da utilização das TIC, como, por exemplo, o risco de tornar os alunos mais individualistas e alienados, podendo contribuir para esquecer os verdadeiros instrumentos de aprendizagem como os dicionários, as enciclopédias, o cálculo, etc., parece ser pacifica a ideia de que a informática e a nova pedagogia são a melhor solução para a aprendizagem.

As vantagens da utilização dos computadores e da Internet na sala de aula são a motricidade, a precisão, a destreza, a motivação dos alunos, a 
autonomia, a aprendizagem na procura, o acesso rápido à informação, o desenvolvimento das capacidades de análise, de classificação e de interpretação de dados e o desenvolvimento da criatividade.

Mas as TIC não são a solução exclusiva para os problemas actuais da aprendizagem. Com efeito, para responder às exigências da NE, a mutação da escola passa por uma revisão profunda dos programas de formação. Será necessária uma ruptura efectiva de forma a instaurar um sistema de educação em concordância com o seu ambiente.

Uma diversidade de novas profissões despontam no horizonte.

É preciso identificar as novas necessidades de formação e saber se as escolas e as Universidades estarão aptas a dar-lhes resposta.

Por outro lado, a escola deve utilizar as novas tecnologias para escolarizar os milhares de crianças e adultos analfabetos que permanecem fora do alcance dos circuitos educativos tradicionais. Com efeito, não se pode esquecer que uma população desfavorecida, ainda muito numerosa, é sistematicamente excluída desta evolução.

As novas tecnologias deverão ocupar um lugar cada vez mais preponderante e crescente na formação nos próximos anos.

$\mathrm{Na}$ linha desta ideia estão Lewis et al (1998) que afirmam que "os estudantes que saem hoje do sistema escolar terão necessidade de ser "reciclados" pelo menos cinco vezes no decorrer da sua vida profissional e metade dos novos empregos exigirão o equivalente a 17 anos de formação a tempo inteiro.

Em suma, parece haver unanimidade quanto ao facto de se afirmar que na NE, as organizações que sairão vencedoras serem aquelas que compreenderam que a informação e a gestão dos conhecimentos estão no centro das transformações.

Nenhuma profissão, nenhuma organização, nenhum empregado será poupado pelas mudanças obrigatórias de práticas em matéria de pesquisa, de selecção das informações e dos conhecimentos, da codificação, do tratamento, da análise, de sistematização, da conservação e da difusão. As TIC virão impor-nos uma mudança draconiana de práticas e, por consequência, de práticas de aprendizagem. Oferecem-nos igualmente uma ocasião única de transformar radicalmente os modos de fazer, em matéria de aprendizagem.

As organizações que vencerão serão as que manifestem a capacidade de aprender com os seus próprios erros (e os seus sucessos) e que saibam adaptar-se rapidamente às mudanças.

As organizações devem criar estímulos para a autoaprendizagem, dando aos seus colaboradores um controlo parcial sobre a orientação e 
desenvolvimento das suas aprendizagens e de os responsabilizar em relação à sua formação.

\section{REFERENCIAS}

AUDET, Michel et al (1996), Renouvellement des services publics et autoroute de l'information: vers un modèle stratégique de transformation et des critères d'aide à la décision, Québec, CEFRIO.

BIBEAU, Robert (1997), L'éléve rapaillé, Ministère de l'Éducation du Quebec, Mars 1997.

DE MASI, Paula; ESTEVÃO, Marcello e KODRES, Laura (2001), "Una Nueva economia?”, Finanzas \& Desarrollo / Junho 2001, Nova Iorque, FMI.

GORDON, Robert J. (2000), "Does the "New Economy" Measure up to the Great Inventions of the Past?" Journal of Economic Perspectives, vol. 14, pp. 49-74.

JORGENSON, Dale W. e KEVIN, J. S. (2000), "Raising the Speed Limit: U. S. Economic Growth in the Information Age", Brooking Papers on Economic Activity, 1, Brookings Institution.

LONGPRÉ, Andrée (1999), Étude sur l'utilisation des technologies de l'information dans l'apprentissage en millieu de travail, Québec, CEFRIO.

OLIVER, Stephen e DANIEL E., Sichel (2000), "The Ressurgence of Growth in the Late 1990s: Is Information Technology the Story?" Journal of Economic Perspectives, vol. 14, pp. 3-22.

STIROH, Kevin (2001), "Information Technology and U.S. Productivity Revival: What do the Industry Data Say?" Federal Reserve Bank of New York Staff Report, $\mathrm{n}^{\mathrm{o}} 115$. 